\title{
Patients and Their Families' Perceptions of Living with Heart Disease: A Qualitative Content Analysis
}

\author{
Maryam Yasrebirad \\ Tarbiat Modares University \\ Sima Mohammadkhan Kermanshahi ( $\sim$ sima098@yahoo.com ) \\ Tarbiat Modares University \\ Mohammadi Eesa \\ Tarbiat Modares University
}

\section{Research Article}

Keywords: Qualitative content analysis, heart disease, crisis perception

Posted Date: March 1st, 2022

DOI: https://doi.org/10.21203/rs.3.rs-1334296/v1

License: (c) (i) This work is licensed under a Creative Commons Attribution 4.0 International License. Read Full License 


\section{Abstract \\ Background}

The aim of this study was to understand patients and their families about living with heart disease.

\section{Method}

This study was a qualitative content analysis study in hospitals in Karaj, Iran. Sixteen patients with heart disease were interviewed. Purposeful sampling method was used in this study. In order to collect data, unstructured interviews were conducted and data were analyzed based on five steps of Granheim and Lundman.

\section{Results}

Data analysis led to the formation of two main categories or themes: "perception of disorder and crisis in life" and "Patient and family abandonment in the care knowledge gap." Cardiac patients experience life-threatening disorders and crises following the disease as a feeling of "inability to control daily life" Which is accompanied by a feeling of physical disability and despair caused by lost physical strength As well as the "confrontation with a vague and disturbing future" which is accompanied by fear of imminent death, fear of disability and a sense of hopelessness for the future, They also experience financial harm and stress in the family as "financial inability to meet living and medical needs", "unpaid expenses", and "loss of financial resources".. Patients and their families also perceive the feeling of being left in a care knowledge gap as "receiving insufficient knowledge of the disease and caring for it" and "facing neglect of family education in the health system." And "receiving insufficient knowledge" as "lack of knowledge about the disease" and "following the incorrect advice of others in self-care".

\section{Conclusion}

Heart patients and their families suffer from financial, physical, psychological and educational crises that have a very unpleasant effect on them and these crises are able to increase the physical and psychological pressures on patients many times over. Of course, sometimes physical disabilities are added to them with old age and complicate the problems. The findings show that there is an urgent need to adopt strategies that can effectively help the patient and her/his family in the face of these crises.

\section{Introduction}

Cardiovascular diseases with 17.9 million deaths per year have been introduced as the most important cause of death in the world. Out of every 5 deaths, 4 deaths are due to heart attacks and strokes, one third of which occur under the age of 70 (1). And the patient and his /her family may seek information, support, and highly effective strategies for managing a wide range of symptoms in reducing future disorders (2).

Studies show that heart patients and their families face a variety of problems in life. Such as intolerance to activity that causes changes in the patient's lifestyle, satisfaction and quality of life $(3,4,5)$. The created physical limitations make the patient's job, family and social life difficult and cause social isolation and depression $(6,7)$. Also, the primary source of depression and despair in these patients is due to the presence of numerous physical symptoms caused by the disease (6). Also, intolerance to activity causes these patients to lose their independence in performing normal life activities and become dependent on others in their care $(8,9)$. The severity and frequency of symptoms for these patients is threatening in nature and the feeling of imminent death causes mood disorders $(10,11,12)$.

Research has also been conducted in Iran, the results of which make us think more about the lives of heart patients. In a study conducted by Abbasi et al (2016) on patients with heart failure, it was shown that However, the findings of this study showed that the quality of life of patients with heart failure in physical, mental, psychological and economic dimensions is better than most of the internal and external studies reviewed and Only the mean quality of life of the study in California (2012) was better than the present study, but the quality of life of these patients is still not good (13). In another cross-sectional study conducted by Jasemi et al in 2013 with the aim of changing the quality of life in patients undergoing coronary artery bypass graft surgery admitted to Imam Khomeini Hospital in Urmia, Concluded that the patients had a moderate level of quality of life and Frequent studies of these individuals showed a significant increase in quality of life only in the physical dimension and no significant difference was found in the social dimension. In other words, different factors affect changes in the dimensions of quality of life that do not work the same (14). These studies are mostly with a quantitative approach and seek to 
determine the extent of patients' life problems based on pre-designed questionnaires. While it is clear that patients' experiences and types of life problems do not fit into the framework of predefined problems only And due to the context and cultural conditions and how to receive services and service delivery systems are different $(15,6,16,17,18)$.

Therefore, quality of life is an individual and mental phenomenon and is completely dependent on the perceptions and experiences of patients. On the other hand, people's efforts to improve the quality of life are influenced by individual, contextual and cultural factors and conditions. Therefore, it is necessary to first determine and explain the type of problems and crises that these patients face according to the culture and living conditions of patients. Then in the future, we can provide appropriate solutions to resolve these crises.

\section{Method}

\section{Study plan}

the aim of this study is to understand patients and their families about living with heart disease.

\section{Participants}

In this study, 16 heart patients and patients' family members were interviewed. Participants in this study should be able to understand Persian well and be able to communicate verbally and be willing to share their experiences, at least 1 year has passed since they became ill (Table 1).

\section{Table 1 - Characteristics of study participants}




\begin{tabular}{|c|c|c|c|c|c|c|c|c|c|c|}
\hline $\begin{array}{l}\text { Number of } \\
\text { participants }\end{array}$ & diagnosis & age & sex & $\begin{array}{l}\text { Marital } \\
\text { status }\end{array}$ & education & job & child & $\begin{array}{l}\text { Accompanying } \\
\text { disease }\end{array}$ & $\begin{array}{l}\text { Years } \\
\text { of } \\
\text { illness }\end{array}$ & $\begin{array}{l}\text { Companions } \\
\text { in life }\end{array}$ \\
\hline 1 & CAD & 83 & Female & Single & illiterate & Housewife & $\begin{array}{l}7 \text { of } \\
9\end{array}$ & Diabetes & 16 & daughter \\
\hline 2 & CAD & 71 & Male & Single & Primary & Shopkeeper & 9 & Prostatitis & 11 & $\begin{array}{l}\text { Daughter } \\
\text { and Sun }\end{array}$ \\
\hline 3 & $\mathrm{HF}$ & 83 & Male & Married & illiterate & Retired & 6 & Obesity & 6 & $\begin{array}{l}\text { Wife and } \\
\text { Sun }\end{array}$ \\
\hline 4 & $\mathrm{HF}$ & 76 & Female & Widow & illiterate & Housewife & $\begin{array}{l}5 \text { of } \\
7\end{array}$ & - & 12 & daughter \\
\hline 5 & $\begin{array}{l}\text { Heart } \\
\text { Valve } \\
\text { Failure }\end{array}$ & 73 & Female & Married & illiterate & Housewife & $\begin{array}{l}4 \text { of } \\
5\end{array}$ & Diabetes & 5 & Wife \\
\hline 6 & $\mathrm{HF}$ & 69 & Female & Married & Diploma & Housewife & $\begin{array}{l}4 \text { of } \\
6\end{array}$ & Diabetes & 10 & Wife \\
\hline 7 & $C A D$ & 72 & Male & Divorced & Diploma & Retired & 2 & - & 10 & Single \\
\hline 8 & $\begin{array}{l}\text { Heart } \\
\text { valve } \\
\text { Stenosis }\end{array}$ & 71 & Male & Divorced & $\begin{array}{l}\text { Associate } \\
\text { Degree }\end{array}$ & Retired & 3 & HTN & 8 & Single \\
\hline 9 & Arrythmia & 70 & Female & Married & Primary & Housewife & 4 & $\begin{array}{l}\text { Diabetes-HTN- } \\
\text { CVA }\end{array}$ & 6 & $\begin{array}{l}\text { daughter } \\
\text { and Wife }\end{array}$ \\
\hline 10 & CAD & 55 & Male & Married & Diploma & Retired & 3 & HTN & 11 & $\begin{array}{l}\text { Wife and } 3 \\
\text { child }\end{array}$ \\
\hline 11 & CAD & 76 & Male & Married & Primary & $\begin{array}{l}\text { Company } \\
\text { shareholder }\end{array}$ & 3 & CABG & 9 & $\begin{array}{l}\text { daughter } \\
\text { and Wife }\end{array}$ \\
\hline 12 & $\begin{array}{l}\text { Severe } \\
\mathrm{HF}\end{array}$ & 76 & Female & Widow & Primary & Housewife & $\begin{array}{l}5 \text { of } \\
7\end{array}$ & $\begin{array}{l}\text { Severe back } \\
\text { pain and foot } \\
\text { pain }\end{array}$ & 12 & daughter \\
\hline 13 & $\longrightarrow$ & 51 & Female & Married & $\begin{array}{l}\text { High } \\
\text { school }\end{array}$ & Housewife & \multicolumn{4}{|c|}{ Patient's wife number 10} \\
\hline 14 & - & 32 & Female & Married & $\begin{array}{l}\text { Associate } \\
\text { degree }\end{array}$ & Employee & \multicolumn{4}{|c|}{ Patient's girl number 8} \\
\hline 15 & - & 43 & Male & Single & $\begin{array}{l}\text { High } \\
\text { school }\end{array}$ & Freelance & \multicolumn{4}{|c|}{ Patient's sun number 3} \\
\hline 16 & - & 24 & Female & Single & $\begin{array}{l}\text { University } \\
\text { student }\end{array}$ & - & \multicolumn{4}{|c|}{ Patient's girl number 9} \\
\hline
\end{tabular}

\section{Data collection}

Unstructured interviews were used to collect information. In total, it was performed with 16 patients and their families for a minimum of 30 minutes and a maximum of 50 minutes. The initial questions were answered and included key questions such as: Tell me about your life after getting sick? How has this disease affected you and your life? Depending on the type of answers to the two main questions, probing questions were asked to explore the depth of their perceptions and experiences. For example, can you please explain more? What do you mean? Can you give an example so that I can understand more of what you mean? The researcher did not induce a response to the participant in any way and allowed them to express their perceptions and feelings. The interviews were recorded with the permission of the participants and recorded on paper at the appropriate time. About 5 participants were not allowed to record the sound and the researcher was forced to take notes of their words. Data collection was continued until data saturation was reached. The data was repeated after the 12th interview. 


\section{Data analysis}

Data were analyzed by conventional content analysis based on 5 steps by Granheim and Lundman. In the first step, the text of the interviews was recorded on tape and immediately implemented verbatim and used as the main research data (Transcribing). In the second step, the recorded audio tape was listened to several times and the handwritten texts were reviewed several times and the decision was made to divide the text into meaning units. In the third step, abstracting of semantic units and selection of codes was performed. According to the participants' experiences, overt and covert concepts were identified in the form of sentences or paragraphs of their words and signifying codes, Then coding and summarizing was done. In the fourth step, based on the continuous comparison of similarities, differences and proportions, the codes that indicated a single subject were placed in a category, and subclasses and classes were categorized and axial codes were formed. Vague and attention-grabbing points, in addition to being reviewed by participants, were also explored in subsequent interviews; in such a way that the points of ambiguity were removed and the position of the codes in each category was completely determined. In the fifth step, at the interpretive level, Classes were summarized and the central concept of each class was identified and the main and abstract concepts were extracted. The concepts were identified based on the description of internal themes in the text and these internal themes were reviewed according to the whole data (19).

\section{Study rigor}

In order to increase the power and accuracy of the study, the researcher uses strategies such as maximum dispersion in sampling, (Table 1), long-term engagement with data, continuous comparative analysis, control by participants in the research (by giving the codes of the first 5 interviews to Them and their evaluation and approval), expert review (showing codes to two important nursing faculty members who were highly experienced in qualitative research), taking evidence-based note-taking, and using citations (20).

\section{Results}

Data analysis led to the formation of two categories: "Perception of disorder and crisis in the patient's life" and "Patient and family abandonment in the care knowledge gap" (Tables 3). The first theme indicates that heart patients suffer from mental and physical limitations and disabilities following the onset of complications Which is accompanied by various stresses such as fear of imminent death, fear of disability, feeling hopeless about the future, injuries and financial stress in the family, feeling of physical disability and despair caused by lost physical strength; that the association of limitations and disabilities with these stresses in patients create a feeling or face of crisis. So that patients understand and pay attention to heart disease with the same life-threatening and disruptive effects and pay attention to it. The second theme shows that a patient with heart disease, along with her family, is left in the community in terms of education and is not valued. The patient does not have a clear understanding of his illness and his family does not benefit from this education. It can be said that we are facing a patient who does not know anything about his illness and is not given proper education and has been completely forgotten and abandoned in the health system in terms of education (Tables 2 and 3 ).

Table 2 - An example of the formation of a subclass

\begin{tabular}{|c|c|c|}
\hline Meaning Units & Codes & Subclasses \\
\hline $\begin{array}{l}\text { "These same daily chores, in the middle of the housework, my breath catches and my heart beats } \\
\text { faster. I'm short of breath. This disease is always on me, Madam. I used to get up at dawn, but now } \\
\text { I sleep until noon. Because I cannot work." (Participant 1). }\end{array}$ & $\begin{array}{l}\text {-Feeling of } \\
\text { helplessness } \\
\text { caused by disease } \\
\text { in life (1) }\end{array}$ & $\begin{array}{l}\text { Feeling of } \\
\text { physical } \\
\text { disability }\end{array}$ \\
\hline $\begin{array}{l}\text { "Because of heart disease, I'm afraid to have sex with my spouse, because I'm afraid my heart rate } \\
\text { will go up and down once. That is why I prefer not to do it" (Participant 5). }\end{array}$ & $\begin{array}{l}\text {-Impotence due to } \\
\text { anxiety caused by } \\
\text { the disease (5). }\end{array}$ & \\
\hline & $\begin{array}{l}\text {-Physical disability } \\
\text { due to heart } \\
\text { disease (9) }\end{array}$ & \\
\hline
\end{tabular}


Table No. 3 - The concept of" leaving the patient and family in the care knowledge gap"

\begin{tabular}{|lll|}
\hline Themes & classes & \multicolumn{1}{c|}{ Subclasses } \\
\hline $\begin{array}{l}\text { Abandonment of the patient and family in the } \\
\text { care knowledge gap }\end{array}$ & $\begin{array}{l}\text { Receiving insufficient patient } \\
\text { knowledge of the disease }\end{array}$ & Lack of knowledge about the disease \\
\cline { 2 - 3 } & Follow the wrong advice of others in self-care & $\begin{array}{l}\text { Neglecting the education of family members } \\
\text { in the health system }\end{array}$ \\
\hline
\end{tabular}

\section{1- Understanding disorders and crises in the patient's life}

This concept indicates that heart patients suffer from physical and mental limitations and disabilities following the onset of complications of the disease, which are accompanied by various stresses such as fear of imminent death, fear of disability, feeling of hopelessness for the future, Financial inability to meet family and medical needs, unmet expenses, loss of financial resources, feelings of physical disability and hopelessness due to lost physical strength; That the association of limitations and disabilities with these stresses in patients create a feeling or face of crisis. So that these patients understand and recognize heart disease with the same life-threatening and disruptive effects and pay attention to it. Characteristics of this concept include three sub-concepts: "inability to control daily life", "facing an ambiguous and worrying future", "injuries and financial tensions in the family".

\section{Inability to control daily life}

The physical limitations caused by the disease have caused the patient to lag behind in life in her body and to see the disease constantly present and watching over them. In this situation, patients who used to take care of their parents in any way or walk well to the store to buy anything are no longer able to do so despite this disease and this disease has made them feel powerless to manage their lives.

"These same daily chores, in the middle of the housework, my breath catches and my heart beats faster. I'm short of breath. This disease is always on me, ma'm. I used to get up at dawn, but now I sleep until noon, because I cannot work." (Participant1).

Also in this regard, when physical disorders occur, it causes the patient's ability to weaken and in turn causes the person to not be able to trust her body mentally. In this case, due to lack of self-confidence, he feels that he has been deprived of life and due to his heart disease, they are not able to express their discomfort in this area and they feel that somehow because they cannot do their previous work. They are not valuable and their grandeur is diminished and this leads to their isolation in society and they feel everyday life. Because they say that they only spend nights and days and they always feel useless and their life is on a straight line and it is not a process and one day it ends. Consider, for example, one of the participants' remarks about the diminished grandeur:

"When you have heart disease, it means you do not have the strength to do anything at all. You get tired quickly. Oh, I do not know if my body pulls or slows down in the middle of work. Well, at one time I was a jerk for myself "(participant 8).

Also, another participant describes the physical disability as follows:

"Because of heart disease, I'm afraid to have sex with my spouse, because I'm afraid my heart rate will go up and down once. That's why I prefer not to do it" (Participant 5).

\section{Facing an uncertain and worrying future}

Patients are quite afraid of death itself, especially since these patients are often elderly and see death approaching due to very old age with illness, even these patients were very nervous because of the fear of death because they felt that with death, they lose all their possessions and have to say goodbye to life. For example: 
"After all heart disease is scary. Do you know what will happen if it stops? These thoughts bother me. Whoever says that he is not afraid of death is lying. I am very afraid. I do not want to lose the result of my efforts."(Participant 6).

Sometimes participants are afraid of the side effects of heart interventions and believe that these interventions cause their disability, for example:

I''m afraid they'll open my heart. Because I have diabetes and they want to take vessels from my legs. Well, what if my wound doesn't heal at all? Do I have to be overweight? How do I walk?" (Participant 5).

After suffering from this disease, these patients develop emotions such as despair, mental and psychological collapse, which these patients express with sentences such as: My condition will never get better, I have no future and no one can help me. Feelings of frustration often cause these patients to lose interest in important topics, activities, events, or people. One of the patients says in this regard:

"I have a feeling. You know, there is no fear. It is a kind of feeling of collapse and breakage. It is a kind of weakening. When you become ill, you just understand what I am saying. The disease itself shows you, for example, you want to climb 4 steps or you cannot do everything you want. I don't even like cooking anymore. I only calm down when I smoke a cigarette, which is temporary "(Participant 7).

Injuries and financial tensions in the family

Many patients cited low-income as a reason for not receiving guests at home and not traveling, and cited the cost of heart disease as exacerbating the disability. That is, they did not consider the disease to be a direct cause of their financial incapacity. For example, one patient says:

"I do not travel at all, because I do not have the money. I'm done sitting in a corner, I also make money, I have to spend on medicine, I can no longer travel, because my salary is really low. It costs money to travel. In addition to the ticket cost, you have to buy a lot of souvenirs, which also cost a lot. I do not know how much I get paid to spend. Even if I want to go to my son in Germany, I am only fresh for a few days and then I have to reach for my pocket. And then this boy sucks me to the end and then he leaves me (patient and researcher laughs) "

(Participant 7).

Sometimes the amount of patients' salaries is enough for daily life, but it is not enough to treat the disease, and in fact, the costs of treating this disease have been able to impose a relatively large financial burden on the family. In other words, they considered heart disease as the cause of their financial inability to meet their medical needs. One patient describes the problem as follows:

"Because I have heart disease, I could not have surgery on my prostate (due to difficulty in regaining consciousness) and instead had to buy expensive drugs (ampoules of one million tomans) to solve the prostate problem, which imposed a heavy financial burden on me because I must inject one ampule a day for a month "(Participant 2).

Heart disease has numerous side costs, which unfortunately in many sections, the costs are not covered. For example, one patient says about the side costs of his disease:

"Every time I come from our city to Karaj and I am admitted to this hospital, unfortunately they do not pay us any fees. Of course, my husband and daughter sleep in the car so that they do not have to pay for the hotel, but it costs a lot anyway. For example, what would happen if the hospital fed the patient's family and provided them a place to sleep? I remember once we came here for angiography, and I had to be hospitalized for two weeks, my wife needed a bath and finally she had to go to a motel, so she could take a shower. We pay all the money for gasoline, we come here and no one asks us at all where you get this money from" (participant 9).

Sometimes, in the face of medical expenses, the family is forced to sell some property, the compensation of which is impossible, which in fact shows the lack of improvement in the quality of life. For example, the daughter of patient number 9 says:

"My father had to sell one of our lands. Of course, they deceived him and gave him some money for the land, but thank God he was finally able to match the money for my mother's surgery" (Participant 16).

2- Leaving the patient and family in the care knowledge gap

This concept includes two sub-concepts called "insufficient knowledge of patients about the disease" and "neglect of family education in the health system".

Receiving insufficient patient knowledge of the disease 
In fact, this sub-concept indicates the fact that patients in the health structure of society have been left alone in terms of education. Another patient attributed his lack of knowledge to the lack of training by the medical staff:

"They do not value a person at all. They do not ask how we are. What happened to my heart? What should I do? Just know the order of the body so that your sheets are flat and the chair next to the bed should not be tilted. They only do unnecessary things. They have to tell people, explain and tell the truth about our medicine. What should we do? "Unfortunately, in a minute, he says something and go, and they don't care at all whether I understand or not?" (Participant3).

Another patient attributes her ignorance to following her parents' words and states:

"Our parents used to tell us that the life is too short, how long do you want to live? Eat and enjoy your life" (Participant 1).

Following the wrong advice of others in self-care is another feature of receiving insufficient knowledge of the disease, which shows that most patients, due to the wrong advice of others, have done things that are very harmful to their health and make it worse. For example, one patient told us about his friend's advice:

"Ma'am, I went to do heavy exercise, I felt bad. Oh, my friend said that you should see Bodybuilders. What vessels do they have? If you exercise, your veins will open in the same way. And they will never close again. I regret that I listened to him, because I was eating TNG for a few days after that "(participant 10).

Another patient describes the reason for not understanding her illness as follows:

"When you see that the doctor and the nurse do not teach you, you have to gather information from everywhere. And it is not clear whether they are right or wrong. For example, when I asked the nurse and saw that the nurse did not give me the Convincing answer, I had to ask the patient's companions next to me. Now it is not clear whether they are right or not" (Participant 11).

Others, regardless of the accuracy of the information, simply prefer to rely on the doctor's words because they trust their doctor.

"My own doctor told me to eat whatever I could, because life is short. I swear in God She herself told me so. I did not ask her why she was telling me that. I just obeyed" (Participant 7).

Neglect of educating family members in the health system

This feature indicates that the patient's family members are not educated and in fact family members who play an important role in caring for their patient, especially during the recovery of the disease, are in complete ignorance. In this regard, one of Patients says:

"When the doctor comes to visit, the nurse comes and throws my baby out of the room. Well, if she stays, she understands what the doctor is saying. Then The next day I go home, she can take better care of me. But unfortunately, I do not understand anything. Oh God, now my daughter does not know my medicine at all, because doctors or nurses do not have time to explain all the medications. They only give us a bad handwriting prescription that we have to wait to see what the pharmacy says so that I can take the medicine accordingly. By God, our intellect is better than these medical staffs "(Participant 12).

Or the sun of the patient number 3 says in this regard:

"Nurses also only stick to bed linen, which must be flat. Or, for example, if someone is not in the room, do they have a little understanding that these things are not useful to the patient? By God, I like so much to tell me what to do now. My father gets better. But nobody tells us anything. They only get stuck in things that are not worth it. Now what if the bedding is not smooth? What's wrong? The Quran is wrong? They are wasting our time. Instead of giving us a little training "(Participant15).

Participant girl number 8 also states in this regard:

"I am not illiterate. They all treat people in such a way that if we are illiterate we know nothing. Ask the nurse a question, for example, what is this medicine and what does it do? The nurse tells me, if you also know this, then what difference do you make with us? Please leave the room. We studied for 4 years to understand these things. Well, yes, you studied, I did not want to know everything, at least tell me a few about these medicines how to give to my father? When to give? You cannot understand many things from the Internet at all. We have to be told what to do. I'm in trouble" (Participant 14).

Or the wife of one of the patients explains the need to have a nurse specialist in the ward: 
"Really, a woman should be a nurse here whose only job is to educate. Because the patient is sick, her/his brain is not working well either. So
educating her/his is not right. We who are healthy can better understand what is what" (participant 13).

\section{Discussion}

The findings of this study showed that heart patients and their families have the experience of "understanding the disorder and crisis in life" and also "abandonment of the patient and family in the care knowledge gap ". Disorders and crises in the life of heart patients include: Feeling of physical disability, Feelings of hopelessness about lost physical strength, fear of imminent death, fear of disability, feelings of hopelessness about the future, financial inability to meet medical and family needs, as well as unmet expenses and loss of financial resources. It also shows the "abandonment of the patient and family in the care knowledge gap", in the form of lack of knowledge about the disease, following the incorrect advice of others in self-care and neglecting the education of family members in their health system.

A study by Ostman et al (2015) was conducted as a grounded theory in Sweden with the aim of discovering discontinuities in life and the factors that contribute to the strength and continuity of heart patients in daily life (21). They achieved the three main concepts of "experiences of discontinuity", "recapturing approaches" and "reconciliation". The experience of discontinuity itself has three subcategories: "the alienated body", "the disrupted time" and "threatened self". One of the concepts that is almost consistent with the category of "perception of disorder and crisis in the patient's life" in our research is the concept of the experiences of discontinuity, which is completely consistent with the category of "the alienated body" and the category of "feeling of physical disability". However, in the research of Ostman, Time and the role of patients on time management have been mentioned, which in the present study, patients have not mentioned in any way. In Ostman's research, the subclass of "threatened self" is almost identical to the subclass of "fear of disability" and the subclass of "frustration with lost physical strength." Ostman's research does not mention the educational and financial problems of patients and their families, which may be due to socio-cultural differences or differences between the Swedish insurance system and Iran.

The reason why the "alienated body" class is aligned with the "feeling of physical disability" subcategory in the present study is that in Ostman's research, the "alienated body" class, was with its physical limitations, permanent illness, isolation, and physical symptoms such as stenosis, Breath and .... In the present study, the meaning of the "feeling of physical disability "and" the feeling of despair caused by the lost physical strength", mention exactly the same cases that perhaps the reason for the similarity of the results is the common nature of heart disease and its effect on the human body and soul that in all countries are almost the same. In the category of "threatened self", which is almost in line with the sub-category of "facing an ambiguous and worrying future" in our research, it is mentioned that because the patient's identity is lost, then she is threatened. In the present study, due to the patient's fear of death and disability and overweight, as well as the feeling of hopelessness about the future, the patient is forced to depend on family members and consider themselves their burden, which causes a feeling of uselessness and isolation in the person becomes ill, which endangers the person's identity. In this regard, the two studies are in the same direction.

Another study by Mirella Fry et al was conducted in 2016 in the UK to explore the experiences of patients with heart failure. In this study, they identified 5 main themes that were of concern to patients. Themes include: "The impact of illness on every day life", "The role of family and friends in providing support ", "relationships with health professionals", "managing multiple illnesses" And "access to health care". In the first theme, patients referred to common problems of heart failure, including physical disability and respiratory symptoms, which are in line with the physical disability sub-category of the present study, but in Mirella's study, there was no mention of frustration caused by physical disability. While in the present study, patients feel very frustrated due to the physical disability caused by the disease, which may be due to cultural differences and not having a happy life in the present study, which could be exacerbated by heart disease. In the category "The role of family and friends in providing support" refers to patients 'concerns about becoming a burden for family, and this is exactly the point that in the present study under the category of "fear of disability" and endangering patients' identities. This view is also consistent with two studies.

Two categories of "relationships with health professionals" and "access to health care" are mentioned in Mirella's research, which patients did not mention at all in the present study. Perhaps one reason is that Mirella has only worked on patients with heart failure and these patients should be constantly monitored, but patients with other heart diseases in the present study do not need follow-up. Another reason may be the difference in the UK health care system, which makes access to specialists far more difficult than in Iran. In the United Kingdom and the United States, the general practitioner sees the patient first and then the patient has to make a long-term visit to a specialist (if needed), But in Iran, the patient can access the specialist directly and with short appointments with any symptom that she/he thinks is related to the heart, and finally, the fifth theme, which is the problem of "managing multiple illnesses" and has been highly emphasized by patients. In this theme, patients complain of disorders of other organs of the body along with heart problems as well as management of drug interactions and multiple medical visits that in the present study, patients did not complain of comorbidities and did not consider them as important as heart disease. This difference may be due to cultural differences, patience and rapid adaptation of Iranian patients to their

Page 9/12 
disease. Instead, the present study emphasizes Financial and educational problems that have not been seen in Mirella's research results. In Iran, contact with health professionals and caregivers is very easy, while they do not receive training from them, and in the UK, access to specialists is very difficult, but patients are educated in the same session (22).

Another qualitative study was conducted by Dhaliwal et al In 2017 in Canada to explore the experiences of financial barriers in caring for heart patients. the study found that patients earning less than $\$ 40,000$ a year did not have access to essential health care and could not afford many drugs, rehabilitation and transportation costs, and that many patients were reluctant to take their medications(23).

These results are all in line with the results of the financial dimension of the present study, which may be due to the fact that Canada is an immigrant country and it is not possible to allocate effective health insurance to all people. In Iran, inefficient insurance and low incomes and lack of special government assistance to heart patients have created these financial problems, but Dhaliwal research has only dealt with the financial dimension and has not paid attention to other dimensions of heart patients' problems.

In 2016, Malhotra et al conducted a study in Singapore to learn about the experiences and preferences of care, communication, and decision-making among patients with heart failure. In this study, they identified six topics, including: "Physical and psychological symptoms", "Financial concerns", "uncertainty and Lack of knowledge about disease", "difficulties in navigating the health care system", "end of life care concerns " and "Fear of burdening family "(24). The theme of "physical and psychological symptoms" refers to disorders such as anxiety, depression, withdrawal from many activities such as shopping, swimming, climbing stairs, meeting friends or going on vacation. The class of" inability to control daily life" is one of the themes of "understanding disorder and crisis in life" in the present study that both are in one direction. In the "financial concerns" of Malhotra's research, patients complain about the high prices of medical care, stating that most of their medical insurance accounts have been emptied and that private insurance can only cover part of the cost of surgery, and so on. The reasons continue to work even in the presence of illness and do not leave their work for treatment so that their insurance is not cut off. This theme is also in line with the category of "injuries and financial tensions in the family" in the present study. On the topic of "lack of knowledge about the disease" in Malhotra's research, patients also express their concern that doctors do not discuss the disease in detail with them and do not educate their families, which is exactly in line with the theme of "leaving the patient and family in the care knowledge gap" in the present study.

On the topic of "difficulties navigating the health system", patients complain that sometimes the general practitioner is unable to diagnose the underlying problem or drug treatment interactions and that the doctor's appointments are too long. This is not in line with the current research in terms of health care system. In this respect, Singapore is very similar to Canada and is very different from Iran. In Iran, diagnoses are easier to give and access to specialist doctors is much easier. In the topic " end of life care concerns", patients believe that if their heart disease is in a serious stage, the doctor or family members should decide whether to continue treatment or not.

But in Iran, patients in sub concept of "fear of imminent death" continue their treatment until the last moment and do not make a decision to terminate the treatment, even the families are with them until the last moment, despite the fact that the patients are too ill. It also seems to be due to differences in cultural and social issues between Iran and Singapore.

Finally, the sixth theme, "Fear of burdening family", which is completely consistent with the sub-theme of "fear of disability" from the category of "facing an ambiguous and worrying future" in the present study and shows that in both Iranian and Singaporean cultures Patients are very afraid of burdening.

\section{Conclusion}

The findings show that heart patients and their families in Iran are facing physical, psychological, financial and educational crises that have created other problems for them. Therefore, due to the negative interaction of heart disease and the process of care and treatment with perceived problems and experiences, this phenomenon can create a vicious cycle between the disease and the problems experienced and perceived in patients and families. Apart from the physical and mental problems, which are present in almost all the studies mentioned, it should be said that there were no signs of financial or educational problems in Sweden, but patients were still afraid of being overwhelmed and losing their identity. In the United Kingdom, Canada, and Singapore, access to a specialist was very difficult, but this problem was not seen in Iran. There are financial crises and educational abandonment of patients and families, especially in Iranian and Singaporean patients. Therefore, in the first step, a written educational program for patients and their families should be considered by specialists in order to ensure the quality and quantity of care. In the second step, financial facilities should be considered by the government to insure all sections of the population in connection with surgeries and the purchase of drugs, in order to eliminate to a large extent the predisposing and aggravating factors of physical and mental disability.. When patients are aware of their illness and are comfortable with financial issues, the side stresses will go away and the main focus of patients and their families will be on the illness itself.

Page $10 / 12$ 


\section{Declarations}

\section{Ethics approval and consent to participate}

This study is part of a research project that was approved by the ethics board of Tarbiat Modares University of Tehran with the ethics code IR.MODARES.REC.1398.044. Permission was obtained from the hospital director and hospital staff, such as educational supervisors and nurses. Written Informed consent was obtained from all of them and they were assured that their names were protected and would not be published in any way and that they could leave the interview at any time. For illiterates participants informed consent obtained from parents or guardian. All methods were carried out in accordance with relevant guidelines and regulations in the study.

\section{Consent for publication:}

Unapplicable

\section{Availability of data and materials:}

The datasets generated or analysed during the current study are not publicly, but data are available from the corresponding author. Because, the file has not yet been translated into English. If you wish, send me a message and I will translate them into English as soon as possible and I will send it to you.

competing interests:

There is no competition for interests.

\section{Funding:}

Not applicable

\section{Authors contributions:}

Dr.Maryam Yasrebirad led the primary analysis and drafted the manuscript and conducted original interviews in the study, worked on the primary analysis of data.Dr.SM was the mentor of research and supported the research in conducting the secondary analysis and commented on drafts of this manuscript. The final approval of the work wad done by Dr.Mohammadi and was my advisor and both guided me in all stages of research.

\section{Acknowledgement:}

We would like to thank Tarbiat Modares University of Tehran for supporting this research, Alborz and Shahid Rajaei hospitals in Karaj and their clinics throughout Karaj, as well as the staff of these hospitals and their patients and families.

\section{References}

1. Dr.Taskeen Khan:Cardiovascular disease .World Health Organization:2021,home page

2. Kitko Lisa et al: Family caregiving for individuals with heart failure: A scientific statement from the American heart association.Circulation:30 April 2020.141(22);864-878

3. Del Buono MG et al:Exercise intolerance in heart failure patients: American college ofcardiology:73:2019:2209-2225

4. Jodi McCoy et al: Pathophysiology of exercise intolerance in chronic disease: the role of diminished cardiac performance in mitochondrial and heart failure patients: BMJ Journal open access:4:2017

5. Samah Hayek etal: Association of exercise intolerance with emotional distress,attainment of social roles and health- related quality of life among adult survivor of childhood cancer:JAMA Oncology:6(8):2020:1194-1202

6. Mandereker Bahall,George Legall,Katija Khan: Quality of life among patients with cardiac disease:The impact of comorbid depression:Health and quality of life outcome:18:2020;189

7. Lucinede da silva et al:The effectsof physical activity on anxiety,depression, and quality of life in in elderly people living in the community: Trends psychiatry psychother: 41(1):2019

8. Li-Yuan SUN et al:Risk factor of cardiovascular disease and their related socio-economical, environmental and health behavioral factors:focused on low-middle income countries -A narrative review article:Iran journal of public health:2015:44(4):435-444 
9. Kensuke takabayashi et al:A decline in activities of daily living due to acute heart failure is an independent risk factor of hospitalization for heart failure and mortality:Journal of cardiology:vol 73:2019:522-529

10. Chrisanthy Vlachakis et al:Human emotions on the onset of cardiovascular and small vessel related disease:In Vivo:32(4):2018:859870

11. Rapaport Lisa: Chronic depression after heart attack tied to increased risk of death: Reuters:Healthcare and pharma:june 2019

12. Jean-christophe,Chauvet-Gelinier,Bernard Bonin: Stress, anxiety and depression in heart disease patients: A major challenge for cardiac rehabilitation: Annals of physical and rehabilitation medicine:vol60(1): June 2017:6-12

13. Abbasi K, Mohammadi E, Sadeghian H. Quality of life in patients with heart failure. Iranian journal of nursing research.2016.Volume11,issue2,May - June,pp:10-23(Persian)

14. Jassemi Madinneh et al: Changes in quality of life in patients undergoing coronary artery bypass graft hospitalization in Imam Khomeini hospital in urmia:Nursing quarterly of medical-surgical: second year: no1(2):2013:45-50(Persian)

15. Olatz Garin et al: Assessing health-related quality of life in patients with heart failure : a systematic, standardized comparison of available measures:Heart Failure Rev: 19(3): may 2014:359 - 67

16. Renata Komalasari, Nurjanah, Maria yoche: Quality of life of people with cardiovascular disease: A Descriptive study: Asian/Pacific Island Nursing Journal:4(2):2019:92-96

17. Yong-Xia Mei et al: Health- Related quality of life and its related factors in coronary heart disease patients: results from the Henan Rural Cohort Study: Scientific reports:2021

18. Mandana Moradi et al: Quality of life of chronic heart failure patients: A systematic review and meta-analysis: Heart failure review:25:2020:993-1006

19. Margaret R.Roller: A quality approach to qualitative content analysis: FQS(Forum: Qualitative Social Research): Vol:No3:Sep 2019

20. Satu Elo ET AL:Qualitative Content analysis : A focus on Trustworthiness: SAGE Journal:2014

21. Ostman Malin et al. Continuity means "Preserving consistent whole", A grounded theory study: International journal of qualitative studies on health and well being,2015,10,1-12

22. Mirella Fry et al: The implications of living with heart failure: the impact on every day life, family support, co-morbidities and access to health care: a secondary qualitative analysis: BMC Family Practice:17:2016:139

23. Kirnvir K. dhaliwal et al: Exploring the impact of financial barriers on secondary prevention of heart disease: BMC Cardiovascular Disorders: 17(61):2017:1-8

24. Chetna Malhotra et al: Living with heart failure: perspectives of patients from Singapore: Proceedings of Singapore health care(PSH): Vol 25(2): 2016:92-97 